\title{
Respiratory distress syndrome and birth order in premature twins
}

D Hacking, A Watkins, S Fraser, R Wolfe, T Nolan on behalf of Australia and New Zealand Neonatal Network

\begin{abstract}
Objective-To determine the effect of birth order on respiratory distress syndrome (RDS) in the outcome of twins in a large premature population managed in a modern neonatal intensive care unit.

Methods-An historical cohort study design was used to analyse the neonatal outcomes of 301 premature liveborn twin sibling pairs of between 23 and 31 weeks gestation from the Australia and New Zealand Neonatal Network 1995 database. Results-Among the 56 twin sibling pairs who were discordant for RDS, the second twin was affected in 41 cases (odds ratio (OR) 2.7, 95\% confidence interval (CI) 1.5 to 5.3). The excess risk of RDS in the second twin increased with gestation and was statistically significant for twins above 29 weeks gestation (OR 4.4, 95\% CI 1.6 to 15 ). Conclusions-There is a significant increased risk of RDS associated with being the second born of premature twins, which appears to depend on gestation.

(Arch Dis Child Fetal Neonatal Ed 2001;84:F117-F121)
\end{abstract}

Keywords: respiratory distress syndrome; twins; premature; birth order; gestation

Historically, perinatal death rates and morbidity have been higher in twin pregnancies than in singleton births. ${ }^{12}$ Moreover, the second twin has been regarded as having a higher risk of a poor outcome. ${ }^{34}$

Recent studies on the effect of birth order on twin outcome have shown contradictory results. ${ }^{5-8}$ Conclusions from these studies were based on relatively small study populations collected over a number of years. The impact of antenatal corticosteroid treatment ${ }^{9}$ and exogenous surfactant use ${ }^{10}$ on the relative outcome of first and second born premature twin siblings has yet to be addressed in a contemporary infant population.

An historical cohort was identified from a large multicentre perinatal database. We sought to investigate what role birth order had on the prognosis of the second twin in a population of premature twin infants cared for in level III neonatal intensive care units. More specifically, we asked the following questions. (a) With the advent of modern perinatal and neonatal practice, is the risk of respiratory distress syndrome (RDS) still raised in the second twin? (b) Does the mode of delivery affect the incidence of RDS in the second twin with respect to the first born sibling? (c) Is there a relation between gestation and the difference in the risk of RDS between twin siblings? (d) With modern obstetric management, is either birth asphyxia or malpresentation of the second twin associated with the risk of RDS?

\section{Methods}

STUDY POPULATION

The Australia and New Zealand Neonatal Network (ANZNN) collects data from all 29 level III neonatal intensive care units in Australia and New Zealand. It collects data on all liveborn infants with a postnatal age of less than 28 days admitted to a neonatal intensive care unit. In addition, it collates information on infants transferred from a labour ward with the intention of admission who are below 32 weeks gestation, under $1500 \mathrm{~g}$ birth weight, require ventilation, or need major surgery. The data are collected prospectively, a random sample of which is later validated against the original cases. Infants with an inevitably fatal congenital anomaly are excluded from the data set. In 1995, 5771 infants were enrolled.

Our study sample, obtained with permission from and in collaboration with the ANZNN, consisted of 602 liveborn twin infants between 23 and 31 weeks gestation (mean (SD) 28 (2.25) weeks) admitted to a neonatal intensive care unit in Australia or New Zealand in 1995. The obstetric estimate of gestation was used throughout this study. This estimate was based on the date of the last menstrual period and the results of antenatal obstetric ultrasound examinations, if performed, during pregnancy.

The study of the relative effect of birth order on premature infants was simplified by analysing the effect within twin pairs, thereby controlling for gestation and differences in antenatal management. We excluded twin pairs where one sibling was stillborn. Twin pairs were included where only one infant was admitted to the neonatal intensive care unit because of the postnatal death of one sibling or because only one sibling required intensive care.

Twin pairs with a discrepancy in birth weight of greater than $20 \%$ were identified. This discrepancy was calculated as the difference in weight divided by the weight of the largest infant multiplied by 100 . Infants were classified as being small for gestational age if their birth weight was below the 10 th centile ${ }^{11}$ when plotted on intrauterine growth curves defined in an Australian population. ${ }^{12}$ An "optimal antenatal steroid course" was defined as more than one dose of corticosteroids given, the first dose of which was received more than 24 hours and less than eight days before the infant's birth. The category "suboptimal antenatal steroid 
Table 1 Characteristics of the study population

\begin{tabular}{|c|c|c|c|}
\hline Variable & $\begin{array}{l}\text { Number of } \\
\text { twin infants }\end{array}$ & Mean & $\begin{array}{l}\text { Standard } \\
\text { deviation }\end{array}$ \\
\hline Birth weight (g) & 601 & 1218 & 363 \\
\hline Gestation (weeks) & 602 & 28 & 2.3 \\
\hline & & Median & IQ Range \\
\hline $\begin{array}{l}\text { Apgar score } \\
1 \text { minute }\end{array}$ & Apgar score & 6 & $4-7$ \\
\hline 5 minutes & 588 & 8 & $7-9$ \\
\hline \multirow[t]{2}{*}{ CRIB score } & 368 & 2 & $1-6$ \\
\hline & & $\begin{array}{l}\text { Number per } \\
\text { category }\end{array}$ & $\%$ of 602 \\
\hline Sex & 598 & & \\
\hline Male & & 318 & 53 \\
\hline Female & & 280 & 47 \\
\hline Race & 414 & & \\
\hline Aboriginal & & 6 & 1 \\
\hline Asian & & 28 & 5 \\
\hline Caucasian & & 368 & 61 \\
\hline African, Indian & & 4 & 0.7 \\
\hline Polynesian & & 8 & 1 \\
\hline RDS & 542 & & \\
\hline Present & & 360 & 60 \\
\hline Absent & & 182 & 30 \\
\hline Survival & 602 & & \\
\hline Survived & & 526 & 87 \\
\hline Died & & 76 & 13 \\
\hline Antenatal steroids & 578 & & \\
\hline Optimal & & 334 & 56 \\
\hline Suboptimal & & 134 & 22 \\
\hline None & & 110 & 18 \\
\hline Surfactant & 592 & & \\
\hline Used & & 332 & 54 \\
\hline Not used & & 265 & 44 \\
\hline
\end{tabular}

RDS, Respiratory distress syndrome.

course" was used to describe cases in which steroids were given less than 24 hours or more than eight days before the infant's birth.

OUTCOME MEASURES

The outcome measures assessed in this study were: Apgar scores at one and five minutes; clinical risk index for babies (CRIB) score $^{13}$; worst arterial blood base excess in the first 12 hours of life; RDS; use of exogenous surfactant (either synthetic or animal derived); oxygen at 36 weeks corrected gestational age; proven infection episodes; significant intraventricular haemorrhage (IVH); mortality. RDS was defined as increasing respiratory distress or oxygen requirements, or the need for ventilator support from the first 6 hours of life together with a chest radiograph showing a generalised reticulogranular pattern, with or without an air bronchogram. A significant IVH was defined as being greater than grade $2 .{ }^{14}$ The following potentially confounding factors were recorded: sex, malpresentation, mode of delivery, birth

Table 2 Comparison of variables between 1st and 2nd born twin siblings

\begin{tabular}{lllllc}
\hline Variable & $\begin{array}{l}\text { Number of } \\
\text { twin pairs }\end{array}$ & $\begin{array}{l}\text { 2nd born } \\
\text { twin only }\end{array}$ & $\begin{array}{l}\text { 1st born } \\
\text { twin only }\end{array}$ & $\begin{array}{l}\text { Odds ratio } \\
\text { (95\% CI) }\end{array}$ & p Value \\
\hline Malpresentation & 283 & 101 & 17 & $5.9(3.5$ to 11$)$ & $<0.001$ \\
SGA & 300 & 20 & 15 & $1.3(0.7$ to 2.8$)$ & 0.5 \\
Intubation at resuscitation & 271 & 24 & 17 & $1.4(0.7$ to 2.8$)$ & 0.4 \\
RDS & 271 & 41 & 15 & $2.7(1.5$ to 5.3$)$ & $<0.001$ \\
Surfactant use & 296 & 53 & 16 & $3.3(1.9$ to 6.2$)$ & $<0.001$ \\
Oxygen at 36 weeks & 288 & 22 & 25 & $0.9(0.5$ to 1.6$)$ & 0.8 \\
IVH & 252 & 7 & 15 & $0.47(0.2$ to 1.2$)$ & 0.1 \\
Mortality & 301 & 24 & 20 & $1.2(0.6$ to 2.3$)$ & 0.7 \\
\hline
\end{tabular}

SGA, Small for gestational age; RDS, respiratory distress syndrome; IVH, intraventricular haemorrhage. weight, and growth for gestational age. Malpresentation was defined as a presentation by breech or transverse lie.

\section{STATISTICAL ANALYSIS}

Unadjusted odds ratios (OR) were calculated from the number of infants in twin pairs that had discordant outcomes $(\mathrm{OR}=$ number of discordant pairs in which the second born twin had a positive outcome divided by number of discordant pairs where first born twin had a positive outcome). Exact Fisher's confidence intervals were calculated for these ORs. ${ }^{15}$ Birth weight was analysed with a paired $t$ test. Apgar and CRIB scores were analysed using the Wilcoxon matched pairs signed rank test. The number of proven infections and the worst base excess in the first 12 hours did not follow normal distributions, hence they were assessed with the Wilcoxon matched pairs signed rank test. In all of these analyses, where one or both twins from a pair had missing data, the pair of twins was dropped from the analysis. To calculate adjusted OR, all infants with complete data were included in logistic regression models for the outcome of interest, with standard errors being calculated using the information sandwich formula ${ }^{16}$ to account for the clustering of observations in twin pairs. A statistical association was deemed significant if the 95\% CI excluded the null hypothesis value (of 1.0 in the case of odds ratios), which corresponds to a significance level of 0.05 for two sided $p$ values. All analyses were performed using the statistical software package STATA. ${ }^{17}$

\section{Results}

STUDY SAMPLE

The study sample comprises 602 premature infants matched into 301 twin pairs. Table 1 summarises the characteristics of this group. The sample included 193 infants with a birth weight below $1000 \mathrm{~g}$ and 252 infants weighing between 1000 and $1500 \mathrm{~g}$ at birth. The study group contained 67 twin pairs in which there was a discrepancy in birth weight of over $20 \%$. The sample included 41 infants who were small for gestational age. One liveborn infant of 26 weeks gestation died in the labour ward before admission to a neonatal intensive care unit.

Of the 301 twin pairs, 113 comprised two boys, 92 comprised one boy and one girl, and 94 comprised two girls. Sex was not recorded for two infants in the study group whose twin siblings were male and female respectively.

Of the 49 twin infants for whom information on RDS was not recorded, there was no bias in birth order and when compared with the 553 infants for which RDS had been recorded, neither was there a significant difference in gestation, birth weight, sex, or mortality between these groups (data not shown).

\section{COMPARISON OF MORBIDITY AND MORTALITY} WITHIN TWIN PAIRS

Table 2 shows that, among the 56 twin pairs who were discordant for RDS, the second twin was affected in 41 cases (OR 2.7), while in the 69 twin pairs discordant for surfactant use the 
Table 3 Comparison of outcome measures between 1 st and 2nd born twin siblings

\begin{tabular}{|c|c|c|c|c|c|c|}
\hline \multirow[b]{2}{*}{ Outcome measure } & \multirow{2}{*}{$\begin{array}{l}\text { Number of } \\
\text { twin pairs }\end{array}$} & \multicolumn{2}{|c|}{ 2nd born twin } & \multicolumn{2}{|c|}{ 1st born twin } & \multirow[b]{2}{*}{$p$ Value $^{\star}$} \\
\hline & & Mean & $S D$ & Mean & $S D$ & \\
\hline Birth weight (g) & 300 & 1214 & 372.4 & 1222 & 355.1 & 0.6 \\
\hline Number of infection episodes & 298 & 0.3 & 0.7 & 0.3 & 0.7 & 0.6 \\
\hline \multirow[t]{2}{*}{ Admission temperature $\left({ }^{\circ} \mathrm{F}\right)$} & 245 & 36 & 2.5 & 36 & 1.0 & 0.4 \\
\hline & & Median & Interquartile range & Median & Interquartile range & $p$ Valuet \\
\hline Apgar score at 1 minute & 293 & 6 & 4 to 7 & 6 & 4 to 8 & $<0.001$ \\
\hline Apgar score at 5 minutes & 294 & 8 & 7 to 9 & 8 & 7 to 9 & 0.2 \\
\hline CRIB score & 184 & 3 & 1 to 6 & 2 & 1 to 6.5 & 0.06 \\
\hline Worst base excess in first 12 hours & 194 & -5 & -1 to -8 & -4 & -1 to -7 & 0.2 \\
\hline
\end{tabular}

$\star$ Paired $t$ test; + Wilcoxon signed rank test.

Table 4 Comparison of $(A)$ the incidence of respiratory distress syndrome and (B) surfactant use between 1st and 2 nd born twin siblings at different gestations

\begin{tabular}{|c|c|c|c|c|c|}
\hline $\begin{array}{l}\text { Gestation } \\
\text { (weeks) }\end{array}$ & $\begin{array}{l}\text { Number of } \\
\text { twin pairs }\end{array}$ & $\begin{array}{l}\text { 2nd born } \\
\text { twin only }\end{array}$ & $\begin{array}{l}\text { 1st born } \\
\text { twin only }\end{array}$ & $\begin{array}{l}\text { Odds ratio } \\
(95 \% \text { CI) }\end{array}$ & $p$ Value \\
\hline \multicolumn{6}{|l|}{ A } \\
\hline $23-25$ & 37 & 3 & 3 & $1.0(0.13$ to 7.5$)$ & 1.0 \\
\hline $26-27$ & 56 & 5 & 3 & $1.7(0.32$ to 11$)$ & 0.7 \\
\hline $28-29$ & 60 & 11 & 4 & $2.8(0.82$ to 12$)$ & 0.1 \\
\hline $30-31$ & 118 & 22 & 5 & $4.4(1.6$ to 15$)$ & 0.002 \\
\hline \multicolumn{6}{|l|}{ B } \\
\hline $23-25$ & 39 & 6 & 3 & $2 \quad(0.43$ to 12$)$ & 0.5 \\
\hline $26-27$ & 60 & 8 & 3 & $2.7(0.64$ to 16$)$ & 0.2 \\
\hline $28-29$ & 66 & 14 & 3 & $4.7(1.3$ to 25$)$ & 0.01 \\
\hline $30-31$ & 131 & 25 & 7 & $3.6(1.5$ to 9.8$)$ & 0.002 \\
\hline
\end{tabular}

second twin was treated in 53 cases (OR 3.3). Moreover, the second twin relative to the first, was significantly more likely to suffer malpresentation and have a lower Apgar score at one minute.

No significant difference was found between the first and second born twins with respect to Apgar score at five minutes or CRIB score (table 3). A comparison of the worst arterial base excess in the first 12 hours showed no significant difference within twin pairs. The incidence of chronic lung disease, as defined by the requirement for oxygen therapy at 36 weeks corrected age, was not significantly different within twin pairs (table 2). IVH and mortality did not vary significantly between the first and second born twins (table 2). There was no significant association between admission temperature and birth order (table 3 ).

There was no significant difference in either birth weight (table 3 ) or growth retardation (table 2) within twin pairs. In twins with a discrepancy in birth weight of greater than $20 \%$, there was no significant association between birth weight and birth order (data not shown). There was no association between sex and birth order (data not shown).

COMPARISON OF RDS BY GESTATIONAL GROUP AND METHOD OF DELIVERY

Table 4 shows that the relative increase in incidence of RDS in the second twin was most pronounced at 30 and 31 weeks, whereas in the 27 twin pairs discordant for RDS, the second twin was affected in 22 cases (OR 4.4). Exogenous surfactant was used significantly more often in the second twin after 28 weeks gestation.

Table 5 shows that the increased risk of RDS and surfactant use in the second twin was not modified by method of delivery. Method of delivery was not associated with the risk of malpresentation (data not shown).

Both the risks of malpresentation and RDS were increased in the second twin. We questioned whether the increased incidence of malpresentation in the second twin could be a cause of RDS. The logistic regression analysis in table 6 shows that only birth order was significantly associated with RDS (OR 1.6).

\section{Discussion}

The predisposition of the second born twin to malpresentation and RDS is well described ${ }^{18}$ in preterm and term infants. However, it has not

Table 5 Comparison of respiratory distress syndrome (RDS) and surfactant use in 1 st and 2 nd born twins from vaginal and caesarean section deliveries

\begin{tabular}{lllllll}
\hline Outcome measure & $\begin{array}{l}\text { Number of } \\
\text { twin pairs }\end{array}$ & $\begin{array}{l}\text { 2nd born } \\
\text { twin only }\end{array}$ & $\begin{array}{l}\text { 1st born } \\
\text { twin only }\end{array}$ & $\begin{array}{l}\text { Odds ratio } \\
\text { (95\% CI) }\end{array}$ & $\begin{array}{c}\text { p Value for } \\
\text { interaction }\end{array}$ \\
\hline RDS after vaginal delivery & 116 & 20 & 3 & $6.7(2$ to 35) & $<0.001$ & 0.13 \\
RDS after caesarean section & 136 & 21 & 12 & $1.8(0.82$ to 3.9) & 0.2 & \\
Surfactant use after vaginal delivery & 128 & 24 & 2 & $12(3$ to 104) & $<0.001$ & 0.08 \\
Surfactant use after caesarean section & 148 & 25 & 13 & $1.9(0.92$ to 4.1) & 0.07 & \\
\hline
\end{tabular}

${ }^{\star} \mathrm{p}$ Value summarises the test of homogeneity of the odds ratios in the two groups.

Table 6 Logistic regression analysis of the relative effects of birth order and malpresentation on respiratory distress syndrome by mode of delivery

\begin{tabular}{lllll}
\hline & $\begin{array}{l}\text { Number of twin sibling } \\
\text { infants }\end{array}$ & Variable & Odds ratio (95\% CI) & $p$ Value \\
\hline Vaginal delivery only & 247 & $\begin{array}{l}\text { Birth order } \\
\text { Malpresentation }\end{array}$ & $\begin{array}{l}1.9(1.2 \text { to 2.9) } \\
0.81(0.4 \text { to } 1.7)\end{array}$ & $\begin{array}{l}0.005 \\
0.6\end{array}$ \\
Caesarean delivery only & 263 & Birth order & $1.4(0.95$ to 2.1) & 0.09 \\
& & Malpresentation & $1.1(0.64$ to 1.9$)$ & 0.7 \\
Vaginal and caesarean delivery & 510 & Birth order & $1.6(1.2$ to 2.1) & 0.001 \\
& & Malpresentation & $0.98(0.65$ to 1.5) & 0.9 \\
\hline
\end{tabular}


been well studied in premature twin pairs in a modern neonatal intensive care setting since the advent of antenatal steroids and exogenous surfactant.

We have shown that the second twin relative to the first is at greater risk of RDS and requiring exogenous surfactant treatment. However, the increased risk of RDS in the second twin was not accompanied by an increased risk of chronic lung disease, as measured by oxygen requirement at 36 weeks. Moreover, there was no statistically significant association between birth order and IVH or death.

A sample of twin pairs allows sensitive controlling of important confounding factors such as gestation when analysing within pair differences in an outcome such as RDS. Chen and colleagues ${ }^{6}$ assessed birth order in 44 twin pairs using an analysis in which the sibling relationship of twin pairs was not taken into account. They found that birth order had no effect on outcome. The size of the study samples and our within twin pair analysis of twin sibling pairs may explain the discrepancy between our findings and those of Chen and colleagues $^{6}$. Nielsen and coworkers ${ }^{8}$ investigated 203 infants from multiple gestations managed since the advent of antenatal steroids and exogenous surfactant treatment. The incidence of RDS was not found to be significantly different between first (52\%) and second born infants $(71 \%)$. Again, the sample size and analytical approach may explain discrepancies with our results.

The analysis of birth order and malpresentation shows that birth order alone was significantly associated with an increased incidence of RDS and surfactant use. Many investigators have attributed the increased incidence of RDS to birth asphyxia caused in part by malpresentation. ${ }^{419}$ We could find no evidence that RDS was related to a significant degree of birth asphyxia. The initial Apgar scores were different between twin siblings at one minute but not at five minutes and were not accompanied by a significant metabolic acidosis, as measured by base excess. Birth asphyxia may have a role in the cause of RDS. However, this is independent of the effect of birth order.

Our findings cannot be explained by differences in birth weight between twin siblings. There was no association between poor growth for gestational age and birth order. A recent report has shown that, in the larger infant of twin siblings with a birth weight discrepancy, there is an increased incidence of bronchopulmonary dysplasia. ${ }^{20}$ Our study group contained 67 twins with a birth weight discrepancy of greater than $20 \%$. However, within this subgroup there was no statistical relation between the larger sibling and birth order.

The association between RDS, surfactant use, and birth order was not independent of gestation. The number of sibling pairs with a discrepancy for RDS incidence and exogenous surfactant use rose with increasing gestational age. The increased incidence of RDS in the second twin compared with the first was significant in the 30 and 31 week gestation group. A larger study may show a significant statistical association of RDS incidence between twins at gestational age groups lower than 30 weeks.

Our study is based on the analysis of twins managed within a number of Australasian level III neonatal intensive care units over one year. It is unlikely that our findings will have been affected by changing practice in these units over time. Given the differences in performance between tertiary and non-tertiary hospitals, ${ }^{13}$ our findings may not be reproduced in studies including infants managed in nontertiary centres.

This study was not designed to assess the relative merits of vaginal and caesarean delivery methods. There is evidence to suggest that the process of vaginal delivery may benefit the first twin. ${ }^{18}{ }^{21}$ This benefit may be absent in the first twin born by caesarean section, leading to a higher incidence of twin pairs who both present with RDS. We observed a trend for a decreased risk of RDS and surfactant use in the first twin born from a vaginal delivery, which was not statistically significant. The optimal method of delivery for premature twins can only be determined through a randomised trial controlled for gestation.

Our study has a number of limitations. All the infants in the cohort were followed closely in the neonatal intensive care unit, but we have no data on their progress since discharge. Although the increase in RDS incidence with birth order in twins was not associated with chronic lung disease, IVH, or mortality, we cannot comment on the effect of birth order on subsequent development. In common with other analyses of historical data, some values were missing because data were not collected at the time or were subsequently lost. Although the amount of missing data was in general small, it could have introduced some bias into the results.

In conclusion, there was a significant increased risk of RDS associated with being second born in premature twin siblings. This association appears to be independent of malpresentation, birth asphyxia, birth weight, appropriate growth for gestational age, and mode of delivery, but depends on gestation.

We gratefully acknowledge Deborah Donoghue, of the ANZNN, for advice on planning the project and help in providing the data. We thank Dr John Thompson for reading the manuscript and for his valuable comments.

1 Potter EL. Twin zygosity and placental form in relation to the outcome of the pregnancy. Am $\mathcal{f}$ Obstet Gynecol the outcome of

2 Ferguson WF. Perinatal mortality in multiple pregnancy. A review of perinatal deaths from 1609 multiple gestations. Obstet Gynecol 1964;23:854

3 Taylor ES. Editorial. Obstet Gynecol Surv 1976;31:536-7.

4 Verduzco RD, Rosario R, Rigatto $H$. Hyaline membrane disease in twins: a 7 year review with a study on zygosity. Am $\mathcal{F}$ Obstet Gynecol 1976;125:668-71.

5 Prins RP. The second-born twin: can we improve outcomes? Am $\mathcal{F}$ Obstet Gynecol 1994;170:1649-56.

6 Chen SJ, Vohr BR, Oh W. Effect of birth order, gender and intrauterine growth retardation on the outcome of very low birth weight in twins. F Pediatr 1993;123:132-6.

7 Burkett G, Bauer C, Morrison J, et al. Effect of prenatal dexamethasone administration on prevention of respiratory distress syndrome in twin pregnancies. $\mathcal{F}$ Perinatol tory distress sync

8 Nielsen HC, Harvey-Wilkes K, MacKinnon B, et al. Neonatal outcome of very premature infants from multiple and singleton gestations. Am f Obstet Gynecol 1997;177:653-9. 9 Crowley P, Chalmers I, Keirse MJNC. The effects of corticosteroid administration before preterm delivery: an 
overview of the evidence from controlled trials. $\mathrm{Br} 7 \mathrm{Obstet}$ Gynaecol 1990;97:11-25.

10 Schwartz RM, Luby AM, Scanlon JW, et al. Effect of surfactant on morbidity, mortality, and resource use in newborn infants weighing 500 to $1500 \mathrm{~g}$. N Engl $\mathcal{f}$ Med 1994;330:1476-80.

11 Battaglia FC, Lubcheno LO. A practical classification of newborn infants by weight and gestational age. $\mathcal{F}$ Pediatr 1967;71:159-63

12 Roberts C, Lancaster P. Australian national birthweight percentiles by gestational age. Med f Austr 1999;170:114 18 .

13 International Neonatal Network. The CRIB (clinical risk index for babies) score: a tool for assessing initial neonatal mance of neonatal intensive care units. Lancet 1993;342:193-8.

14 Papile LA, Munsick-Bruno G, Schaefer A. Relationship of cerebral intraventricular hemorrhage and early childhood neurologic handicaps. $\mathcal{F}$ Pediatr 1983;103:27.

15 Rothman KJ. Modern epidemiology. Boston: Little, Brown and Company, 1986:264-7.
16 Stata Corporation. STATA statistical software user's guide. College Station, TX: Stata Press, 1997;Release 5.0:235-9.

17 Stata Corporation. STATA statistical software. College Station, TX: Stata Press, 1997; Release 5.0.

18 Arnold C, Mclean F, Kramer M, et al. Respiratory distress syndrome in second-born versus first-born twins: a matched case-control analysis. $N$ Engl $f$ Med 1987;317:1121-5.

19 Chevenak FA, Johnson RE, Berkowitz RL, et al. Is routine cesarean section necessary for vertex and vertex-transverse twin gestations? Am f Obstet Gynecol 1984;148:1-5.

20 Sonntag J, Waltz S, Schollmeyer T, et al. Morbidity and mortality of discordant twins up to 34 weeks of gestational age. Eur F Pediatr 1996;155:224-9.

21 Pearson, Murphy BE. Human fetal serum cortisol levels related to gestational age: evidence of midgestational fall and a steep late gestational rise, independent of sex or mode of delivery. Am 7 Obstet Gynecol 1982;144:276- 